\title{
Public value creation using social media applications for the local government context: a pilot case study
}

\section{Althaqafi Turki}

School of Information Technology

Monash University

Melbourne, Australia

Turki.Althaqafi@monash.edu

\section{Susan Foster}

School of Information Technology

Monash University

Melbourne, Australia

sue.foster@monash.edu

\section{Md Mahbubur Rahim}

School of Information Technology

Monash University

Melbourne, Australia

md.mahbubur.rahim@monash.edu

\begin{abstract}
Social media applications are receiving growing attention from local government agencies as they have the potential to offer public values to those agencies as well as providing benefits to citizens by enhancing public engagement and innovating public services. Despite the growth in the literature on social media, there is still limited understanding on how public value is created through the use of various social media applications in local government context. To address this concern, we have developed a model to investigate public value creation using social media applications. The model is evaluated using a pilot case study at a large Saudi Arabian municipality. The model and empirical evidence together contribute towards establishing a theoretical foundation for research into the impact of social media applications for public value creation. In addition, council managers can learn useful lessons drawing on our findings on how best utilise social media applications for local government matters.
\end{abstract}

Keywords: Social Media, Public Value, Local Government, Case Study, Saudi Arabia 


\section{Introduction}

Social media is an important communication tool for use between government agencies and their constituents. It enhances the effective delivery of public services (Merickova, Svidronova, \& Nemec, 2016), supports awareness on public safety, and facilitates establishment of democracy (Mergel, 2013). For the context of the local government, social media is vital to fostering commitment with important stakeholders and promotes innovation in the public service sector. Enhancing public engagement and public services innovation is crucial in achieving public values such as fairness, trust, transparency and integrity. Despite the vast amount of literature on the benefits of social media to government agencies', no studies have systematically focused on the concept of 'public value' involving the application of social media for the context of local government. There exists limited studies on the relationship between social media capability, trust in social media, public engagement, public service innovation and the resulting public values for the local government context. Consequently, scholars are of the opinion that the Information Systems (IS) community should take the initiative of investigating these aspects (Johannessen, Sæbø, \& Flak, 2016; Omar, Scheepers, \& Stockdale, 2013).

This argument is valid from a local government context for developing countries where the population is known for their wide use and reliance on social media applications to express their concerns and viewpoints towards their government (Dini \& Sæbø, 2016). In Saudi Arabia where this study is conducted, social media use is wildly popular. The number of internet users in Saudi Arabia skyrocketed to reach 30 million people by 2018, while 25 million are active social media users (Insight, 2018). However, it is not known yet how local government agencies are using social media to engage with citizens. According to 'Saudi Arabia Vision 2030', the government is undergoing major, dramatic, economic, cultural and social transition plans by creating more open and transparent programs (SaudiVision, 2017). Due to the nature of social media applications (e.g. openness, two-was communications), citizens and government officials alike are encouraged to better utilise these applications to achieve the 2030 vision goals. Being motivated by these, this study seeks to address the following research question: How does the use of social media applications by local government agencies create public value?

As part of an ongoing study, we recently presented the development of a conceptual model of how public value is created using social media applications (Althaqafi, Rahim, \& Foster, 2018). In this paper, we report an empirical evaluation of a public value creation model based on a pilot case study conducted in one large Saudi Arabian municipality. From this case, we provide a rich description of how social media can be used to create public value for local government context. We find that social media capability and trust in social media can affect the level of public engagement. We also find that social media applications contribute to create public value through providing public services innovation. This paper also presents a methodological contribution to IS research, as we provide a detailed application of a critical realist ontology and methodology for social media research context. The paper is organised as follows: First, the related background literature is reviewed. Next, the model, its theoretical foundation, propositions development, and evaluation are presented, and some conclusions are drawn.

\section{Background Literature}

The notion of public value, although initially emerged in the public administration (PA) literature (Andersen, Jørgensen, Kjeldsen, Pedersen, \& Vrangbæk, 2012), IS scholars is beginning to receive attention in recent years to public value created by the use of social media (Aladalah, Cheung, \& Lee, 2016). Following the approach of Webster and Watson (2002), a systematic literature review was performed using Monash library databases including EBSCHOST, PROQEST and SPRINGER. Various combination of such search terms as social media use, government, local government, municipality, Gov2.o, social network and (among others) were used to identify the relevant academic papers on social media use by public sector agencies. From the review, we identified 71 papers. As a result, several themes related to our research emerged: social media capability, trust in social media (IS perspective), public engagement, public service innovation and public value (PA perspective), these concepts are individually described below.

\subsection{Social Media Capability}

Multiple definitions exist for social media capability in the IS literature (Braojos-Gomez, BenitezAmado, \& Llorens-Montes, 2015; Kane, 2015). Moreover, social media capability is also equated as social media affordance (Dini, Wahid, \& Sæbo, 2016). These divergent ideas discussed in the existing literature can cause confusion due to their similar meanings. To avoid such confusion, we have integrated both concepts into a single construct, which we refer to as social media capability. Therefore, we adapted the 
definition of social media capability from Braojos-Gomez et al. (2015) to "the ability of local government agencies' to utilise social media functions, features and characteristics for fostering public engagement to execute government activities". A set of three main dimensions form the social media capability construct: functions, features and characteristics. Social media functions such as information editability, and private messaging event creation allow the user to perform certain activities that are typically expected and required to complete required tasks. Features represent the aspects of the social media applications systems that, while not necessary, provide enhancements to better complete required tasks such as manage contacts capability, social media analytics capability, Access content capability, Customisable modules capability, and anonymity (Rauniar, Rawski, Yang, \& Johnson, 2014). A social media characteristic can be described as the special, distinctive aspects of the social media applications in terms of interactions between two parties such as information sharing, visibility, interactivity, idea storming capability.

\subsection{Trust in Social Media}

IS literature further highlights the importance of trust from a social media context (Mcknight, Carter, Thatcher, \& Clay, 2011). Trust has been addressed from two perspectives: a) trust in government behaviour through business processes performed on social media applications (Park, Choi, Kim, \& Rho, 2015), and b) trust in people, either government officials or citizens in their use of social media applications (Hong, 2013). However, trust in the technological part of social media has remained largely ignored (Tams, Thatcher, \& Craig, 2018). We have however adopted the viewpoint of (Mcknight et al., 2011), who defines trust in technology as the actual relationship between users and the technology in terms of functionality, helpfulness and reliability. Functionality refers to the question of whether or not the technology functions as promised by completing tasks that are required. Helpfulness represents the users' beliefs that the technology provides sufficient support and represents a thorough help and support function (Mcknight et al., 2011). Reliability means that the technology or IT artefact operates continually (i.e. with little or no downtime) or responds predictably to inputs (Mcknight et al., 2011).

\subsection{Public Engagement}

Public engagement has gone through many developmental stages in different contexts and has been affected by ideological, social, political and methodological meanings (Nabatchi \& Amsler, 2014). Due to the emergence of Information Communication Technology (ICT) tools in government agencies, there is now a shift from traditional communication to digital communication. As a result, the concept of public engagement is still taking place but through new means of digital communications like egovernment and social media, which are built on web 2.0 technology. Various levels of public engagement have been reported in the literature. For example, in Arnstein (1969), a famous ladder of citizen participation, there are three levels of public engagement which are further broken down into eight levels. In contrast, Men and Tsai (2012) have only two levels of communication. In this paper, we adopt classifying public engagement into three levels: Information Dissemination, Consultation and Cocreation. The Information Dissemination level refers to the posted information on social media applications by citizens and government officials for their own benefit. Consultation is a limited twoway communication channel that allows stakeholders and citizens to contribute their opinions on some issues; the objective of this level is to collect public feedback. Consultation could be initiated by either the government or the citizens, but the change is led by the government. Citizens also expect a high response rate at this level. However, the main objective of this level is not to directly involve citizens in the decision-making process but rather to collect their feedback for future service improvement. Finally, the Co-creation level involves citizens on social media applications in decision-making processes such as planning and designing policy, services and strategies, and allocating budgets, etc. This phase could be led by citizens through citizen-to-government sourcing or citizen-to-citizen interactions where the government plays a supervisory role.

\subsection{Public Service Innovation}

Recently, there has been a great deal of professional and scholarly interest in 'innovation' in the public sector (Mark Harrison Moore, 1995; Mulgan \& Albury, 2003; OECD, 2005). However, there exists no universal definition of innovation for the public-sector context. In this paper, we have adapted the definitions of (Criado, Sandoval-Almazan, \& Gil-Garcia, 2013; Mulgan \& Albury, 2003; OECD, 2005) as follows: "The implementation of a new or significantly improved product (good or service), or process which results in significant improvements in and/or a complete transformation of outcomes in the form of efficiency, effectiveness and/or quality". We have combined multiple definitions to include different components of public service innovation such as type of change, transformation or innovation. This definition is incorporated in the four categories of public service innovation developed by (Brown \& 
Osborne, 2012). The four categories are 1) developmental change (the significant improvement of existing services delivered to existing users), 2) expansionary innovation (utilising an existing service and delivering it to a new group of users); 3) evolutionary innovation (creating new services for current users); 4) total innovation (supplying new services to new users).

\subsection{Public Value}

Moore (1995) who coined the term public value, identified the basic idea behind public value as being the 'Strategic Triangle'. The strategic triangle consists of three important factors: creating something substantively valuable, legitimate and politically sustainable, and operationally and administratively feasible with available internal and external capabilities. Drawing on the strategic triangle, public organisations can generate value that could be genuinely considered useful for the citizens in many ways, such as improving the quality of public services through three main sources of public value: outcome, trust and services (Kelly, Mulgan, \& Muers, 2002). Public values range from professional and managerial values to encompassing issues such as social and democratic values. Many studies have classified public values based on different dimensions (Andersen et al., 2012; Hood, 1991; Jørgensen \& Bozeman, 2007; Kernaghan, 2003). From a thorough review, the taxonomy provided by Kernaghan (2003) is chosen for this research project as the basis for evaluating public value. Kernaghan (2003) has classified public value into four dimensions including ethical values, professional values, democratic values and social values. They have been used to facilitate the interaction between government officials and citizens. The taxonomy of Kernaghan (2003) has been chosen for this study because a) most classifications being proposed lack even the most basic requirements to assess their validity and usefulness, except for Kernaghan (2003) work, which has not yet been criticised (Rutgers, 2008); b) it has been classified based on public services; c) there are many duplications in the value sets of other taxonomies; d) it introduces professional values as a separate dimension, which relates more to internal activities such as effectiveness and efficiency; and e) each dimension in Kernaghan (2003) taxonomy is applicable to social media use in the government context.

\section{Conceptual Model}

This conceptual model presents the five main constructs chosen from the relevant IS and public administration literature sources described above in section 2. This model is a process based model in nature. This is because it explains how an outcome (social media enabled public value) is reached through a sequence of activities like social media enabled public engagement and social media enabled public service innovation (Newman \& Robey, 1992).

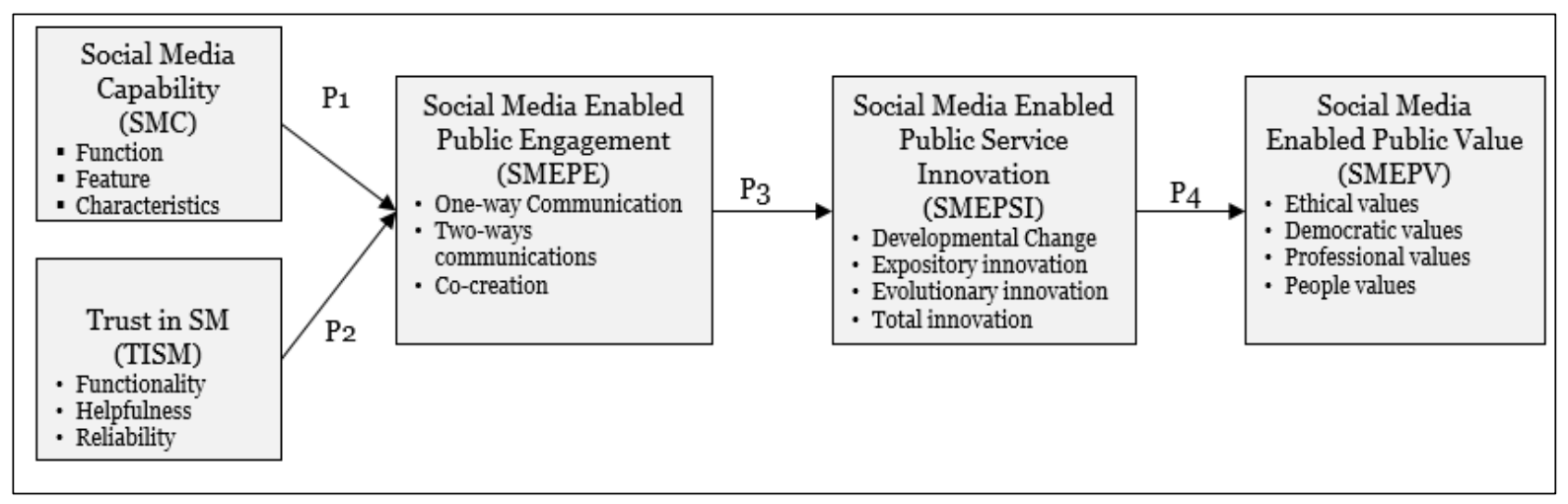

Figure 1: Conceptual Model

As represented, Figure 1 identifies the linkages between the constructs and the propositions that reflect these linkages. These linkages between constructs are discussed:

Social media capability association to social media enabled public engagement: The local government agencies' proficiencies in sharing, co-creating, discussing and modifying user-generated content facilitates information sharing, interaction and connection with citizens (Linders, 2012), thereby improving citizen participation and interrelatedness. For example, citizens might engage in the council's social media applications and want to stay informed about its activities and future launch of services (Oré \& Sieber, 2011), or there could be collective intentions to deliver better and higher quality services. Moreover, providing a useful and easy way to access information through social media influences the public to interact with others and return to the organisations' social media applications and websites (Kane, 2015; Malsbender, Hoffmann, \& Becker, 2014). Social media capability is used to engage with citizens with the aim of developing service innovations. These capabilities (e.g. information sharing, 
visibility and editability) can be successfully utilised to support public engagement at various levels. This directly leads us to the following proposition:

P1: Social media capability is positively related to social media enabled public engagement.

Trust in social media associated to social media enabled public engagement: The public's degree of trust of the government is a measure of the extent to which the government achieves its goals. The relationship between trust in social media applications and public engagement has also been reported in recent studies (Park, Choi, Kim, \& Rho, 2015; Warren, Sulaiman, \& Jaafar, 2014). Aladalah et al. (2016) argued that using social media applications encourages a feeling of belonging, boosts government legitimacy and increases trust in government and therefore more engagement is to occur. Likewise, Park et al. (2015) have reported a number of factors related to social media use affecting the level of confidence between government and citizens. Warren et al. (2014) noted that trust in using social media applications influences the public's propensity to engage with government officials. Similarly, concluded that the direct involvement of a government's leading officer is increased because the public's trust using social media applications. Therefore, the following proposition is derived:

\section{P2: Trust in social media applications is positively related to social media enabled public engagement.}

Social media enabled public engagement associated to social media enabled public service innovation: Public engagement between citizens and government officials in the development and subsequent implementation of innovations in public services is important in terms of the success of the public service innovation process (Merickova et al., 2016). This requires digital intermediate channels such as social media to produce innovation in public services. In general, ICT in the production of innovation in services for the public sector has received less attention in the broader IS literature. However, several authors have addressed the potential of social media for the innovation of public sector organisations (Criado et al., 2013). It is argued that the engagement between citizens and government officials in the process of public services delivery could bring innovative ideas (Linders, 2012). Mergel (2013) suggested that the innovation in public services is not limited to the use of social media applications, but compared with other ICT applications, public engagement is publicly observable. Therefore, the following proposition is derived:

P3: Social media enabled public engagement is positively related to social media enabled public service innovation.

Social media enabled public service innovation associated to social media enabled public value: Emerging alternative approaches to public service delivery and changing social expectations make social media use at the local level a prerequisite. Today, public service innovation constitutes a vital part of a countries' administrative reforms as governments question the traditional concept of public service delivery that often care about efficiency and effectiveness of the business processes). Therefore, alternative approaches have been introduced by facilitating innovation in public services and allowing citizens to be part of the process of designing, planning and implementing innovation (Brown \& Osborne, 2012). Alongside this, the public value introduced by Moore (1995) could go hand in hand with innovation in public services. Citizens expect public institutions to not only provide public services in an efficient way but also in a participatory and accountable way. In fact, it is believed that the involvement of citizens through social media applications in every stage of public service design and delivery, as an innovative approach, can help improve public services through a better understanding of citizens' changing priorities and through the accumulation of citizens' information and ideas (Linders, 2012). In return, public value can be maximised. Therefore, the following proposition is derived:

P4: Social media enabled public service innovation is positively related to social media enabled public value.

\section{Research Method}

In the last decade, there has been a growth of interest in Critical Realism (CR) as an alternative to positivist and interpretive IS research (Volkoff \& Strong, 2013). With no existing framework to explain the associations between the various constructs we have identified, our study represents a theorybuilding endeavour conducted from a critical realist ontological perspective. This study is intended to investigate how and why local governments use social media applications. This study can be described from IS evaluation research (Dwivedi, 2009). A critical realist IS evaluation research searches for mechanisms and conditions to explain why events happen, rather than predicting events, and aims to develop and test theories grounded in practice (Carlsson, 2003; Dobson, Myles, \& Jackson, 2007). As an initial step in critical realism studies, our study focuses on possible causal mechanisms (trust in social 
media, social media capability, public engagement, public service innovation) which could produce events (public value), rather than descriptions of empirical events themselves (Sayer, 2000).

Determination of the method to be applied in research is fundamental. A CR case technique is appropriate, especially in plainly bound, but composite, occurrences such as organisations, inter organisational relationships or nets of connected organisations (Fletcher, 2017; Tsang, 2014). In determining causality, the researcher may be required to go beyond or narrow the preliminary boundary, because it is clear that the causal mechanisms are more narrowly focused than previously thought. Yin (2017) asserts that questions about 'how' and 'why' are better answered through qualitative methods. In our study, we used a single case approach in capturing mechanisms (social media capability, trust in social media, public engagement and public service innovations that are interlinked to produce events 'public value'. The unit of analysis in this study would be a single local government agency that implemented at least one social media application for its services activities. Data was collected at a large municipality in Saudi Arabia. This municipality was chosen due to its high level of interaction with citizens using social media applications as well as it is one of the largest municipalities in Saudi Arabia. To gain a deeper understanding, semi-structured interviews were undertaken with five key government officials' informants (e.g. Deputy Mayor for regional areas, Deputy Mayor for IT, Public relation manager, Social media coordinator and Bridges construction manager). They have working experience with the council for over 10 years, on an average. The duration of the interviews was approximately 30 minutes. The interviews took place between December 2017 and January 2018.

Data coding analysis through deductive and retroductive reasoning is important in CR qualitative research. A coding scheme was developed based on the interview questions derived from literature. Coding scheme example in Appendix 1. Data coding analysis was done at two cycles following the approach of (Saldaña, 2016). In the First Cycle Coding, we use a primarily provisional coding. It begins by compiling a predetermined "start list of set codes prior to field work" (Miles \& Huberman, 1994). These codes can be anticipated categories generated from literature reviews. Codes were created to label a chunk of a 'descriptive paragraph to group empirical data into themes and subthemes reflecting social media capability, trust in social media, public engagement, public service innovation and public value. After that, the Second Cycle Coding methods are performed; In this case, pattern-matching coding is applied. Codes and propositions were evaluated using pattern matching (Yin, 2017), which enabled us to identify an emergent theme, configuration, or explanation about relationships among constructs in our model. This is well suited for the implementation of retroductive reasoning to determine how and why contingent conditioning of causal mechanisms may or may not impact real events (Fletcher, 2017).

\section{Empirical Findings and Discussion}

In this paper, we are not providing evidence covering the influence of all dimensions involved in each construct, only one or two dimensions for each construct is presented. The extent of evidence varied from one dimension to another. For example, the dimension of one-way communication in SMEPE construct received high volume of comments, whereas the co-creation dimension received the least. All five constructs have been evaluated from key government officials' informants' perspectives. Each proposition is discussed below:

Proposition 1: Our findings show that there is a positive association between social media capability and public engagement. Information sharing capability can be achieved through the ability of the council to create hashtags on Twitter for engaging with citizens about events, awareness campaigns, and services. The public relations manager supported this view when he stated:

"Hashtags were created, and many people made positive comments. Such hashtags [information sharing] help to increase engagement, awareness, and support law enforcement" (Code: P1-SMC-PE$P$-GO-o64-I1).

The capability of social media (information sharing, for example) is used by municipality government officials to enhance citizen engagement. Hashtags are created on Twitter application. When a hashtag is created, it invites citizens to collaborate with government officials about certain issues, such as current and future services, events, and businesses. Such mass collaboration requires a high level of engagement where users are able to generate content. As such, social media applications have reshaped the nature of discussion by moving it from the real world to the virtual world. One advantage of information sharing capability through creating hashtags is that they help improve service quality. This is because municipality decision-makers can gauge citizens' collective thinking about the municipality's performance. Decision-makers can thereby transform what is being discussed on hashtags into action. Social media-generated data from hashtags, posts, and comments should be analysed using data mining techniques to better understand what users are looking for on various social media platforms (Bekmamedova \& Shanks, 2014). Such techniques open up new venues for engagement between organisations and end users. According to Bekmamedova and Shanks (2014), to perform a customer 
insight mining task, an organisation needs to allocate two important elements: skills and practices. Skills are embodied in individuals or teams who actively manage or accomplish organisational tasks. Practices serve as a means of accomplishing organisational tasks and as mechanisms for storing and accessing knowledge about the most effective ways to accomplish those tasks. Our results show that the municipality demonstrates little interest in using such techniques because all available data mining software does not support the Arabic language, which used across the social media applications. Therefore, the second key element for conducting such an activity is missing. However, data monitoring can be done manually by identifying the most active and engaging social media accounts through which relevant issues can be tracked and documented. Data monitoring involves identifying, correcting, and evaluating operational deficiencies to identify opportunities for improvement (Linders, 2012). According to the social media coordinator:

"Data analysis techniques are not so popular in the government sector. They...do not have the technical resources... [or] the expertise. Also, data analytics software for social media do not support [the] Arabic language, so we in the IT department have just three people responsible for social media data, so we monitor specific accounts to know what [is] exactly going around. These accounts usually are active in reporting problems" (Code: P1-SMC-PE-P-GO-0010-I2).

Regarding the capability of social media functions, like information editability, the municipality officials spend a good deal of time and effort crafting and recrafting a communicative act before it is viewed by citizens. However, deleting or updating information after being posted on a public account may have negatively effects on public engagement. According to the social media coordinator:

"In Twitter, we cannot edit information after is officially published, but we can still delete it and tweet again, but by the time to do that, people will take screenshots of it, and that will be really embarrassing.... People will think of us as...being less transparent where we should be more transparent, so we have to make sure that every tweet is revised and good to be published. In Facebook we can do that, but still the same concept [is] applied. We have to make sure that every post is okay to be seen by citizens" (Code: P1-SMC-PE-P-GO-OO1-I2).

In line with our findings, Treem and Leonardi (2013) stated that the capability of editability is vital for broadcasting high quality information; however, this is only applicable before posting on social media public accounts.

Proposition 2: Trust in social media is not found to be an issue of concern for public engagement. In fact, government officials at the council did not express any trust issues related to social media technology, such as system crashes, loss of data, or insufficient support. This view was supported when the manager of bridge construction manager stated:

"Social media has great echoes. Now, instead of writing a letter addressing his/her concern, all people can address their concern on social media.....Now all government agencies [including councils] are using social media to communicate with citizens...so, in terms of trusting social media as technology, yes, they are trustworthy, and you would not see high authorities using them [social media applications] to engage with citizens" (P2-TISM-PE-P-GO-O34-I5).

Some social media applications are run by third parties. The difference between social media applications and enterprise applications, like ERP or Oracle, is the level of control that the end users have (Omar et al., 2013). On social media applications, users can customise their preferences, security, and privacy settings, to a certain extent, but they have no control over the application, whereas in enterprise systems, users have greater control. This is because social media applications are free and developed by third parties. Despite this, however, those third parties are trusted and supportive and users experience fewer technical and functional problems. This view is supported by the Deputy Mayor for IT when he stated:

"I think people trust using social media functionalities. The evidence of that [is] the huge number of people using Twitter, Facebook, and WhatsApp. This is because we do not have to worry about the [se] application[s] like...other applications in [the] IT department. We are just end users and we never experience any major outage or anything like that" (P2-TISM-PE-P-GO-O28-I6).

Cultural conflicts may result in less trusting the technology. Srite (1999) asserted that new developed technologies in western culture are more likely to be less trusted and used in eastern cultures. This is due to the culture conflict resulting from trust issues. However, our result indicated an opposite result where social media developed in western cultures used heavily by Saudi citizens and Saudi government agencies as well.

Proposition 3: The degrees of different public service innovations require different levels of public engagement. Our finding highlights that, for developmental changes that occur over time, it may be suitable to use one-way communication for public engagement. For example, the social media coordinator mentioned that one-way communication is good for delivering messages to citizens in which a development may occur over time: 
"Social media is a means to share any kind of information about the council's services, announcements, news, etc." (Code: P3-PE-PSI-P-GO-O65-I2).

Services are already provided through other alternative channels of communication, such as telephone, email, and face-to-face meetings. The difference in public services innovation being delivered through social media compared to other channels is that government agencies are disseminating information about current services, which are open to the public discussion (Linders, 2012). Therefore, the social media capability of making comments and the information made available to the public affect the public value created through social media applications (Lee-Kelley \& Kolsaker, 2004). However, due to the low level of engagement, which shows the reduced enthusiasm of citizens to seek more and better public services, the process of change takes longer (incremental change). Local government agencies can analyse the comments and replies of citizens to general information and news posted by government officials. Generally speaking, local government officials play a supervisory role regarding what is being said and commented on. This ideation process does not require a high level of interaction.

For expansionary innovation, local government has the willingness to provide high quality public services to citizens who have never received such services (Brown \& Osborne, 2012). The expected level of engagement in this stage is high, and local governments should make efforts to advertise, engage, and attract citizens (Linders, 2012). New users who might live in rural areas may find it more difficult to communicate directly in real time with local government officials. Social media applications can thus help to convey their messages to appropriate public service providers (Criado et al., 2013). Nonetheless, changes made to public service provisions will take place over a relatively long period of time with minor improvements. This might be because citizens have high demands for public services to be delivered in short periods of time, local government service providers may not be making enough of an effort to meet the needs of citizens, or the government objective at this stage might be to concentrate on existing services, making significant improvements to them, and then distributing them to other users. According to the social media coordinator:

"If we are looking for specific feedback about any issue, then yes, social media does help the council to do that" (Code: P3-PE-PSI-P-GO-O41-I2).

In the evolutionary innovation, the municipality has the willingness to provide high quality new public services that did not exist before. This could be initiated and led by local governments or initiated by citizens and led by governments. Senior government officials could raise initiatives to innovate new public services by receiving new ideas through social media applications, as such applications allow new ideas to spread among government officials and the public (Criado et al., 2013; Malsbender et al., 2014). The level of public engagement will be noticeably increased, and co-creation in the designing, planning, and policymaking stages of public services will take place. High quality public services delivered through the synergistic effect of government official-citizen collaboration in terms of time/cost savings and innovations is supported by the use of social media applications. Governments and the public can benefit from providing high quality new services. This is most noticeable in the level of engagement during projects/tasks, emergencies, and natural disasters. This view is supported by the public relation manager when he remarked:

"Food truck for example. Yeah, it...started from a group discussion on WhatsApp among council's staff, so they decided to do it and be the first council to do it. It was then promoted through Twitter and we made [a] campaign on how to get the licence" (Code: P3-PE-PSI-P -GO-055-I3).

Proposition 4: Mark H Moore (2014) stated that public value consists of both "utilitarian" and "deontological" values. Utilitarian values are concerned with the good at individual and collective levels, and deontological values reflect what is right, fair, and just at individual and collective levels. For utilitarian values (people and democratic values), delivering public services to create value through social media has become an interest of local government agencies. Our results show that this is consistent with our argument in Proposition 4, where various types of public service innovations enabled public value creation. For example, the social media coordinator indicated that social values, such as fairness and caring, can be created through social media when citizens living in rural areas ask for the same services that are offered in urban areas (Merickova et al., 2016). According to the social media coordinator:

"People now are sharing more information on social media about their society, so if someone saw a broken street or rubbish or anything, he/she will take a picture of it and report it to the council or even post it...to their personal account or other accounts interested in the city. Also, the impact of social media on these values, I guess, is greater than any other types of value. Social media helped the volunteer work... [and] people start[ed] offering help" (Code: P4-PSI-PV-P-GO-O5O-I2).

Deontological values (ethics and professional) are more internal within the municipality, where the government official is seeking his/her interest over citizens' interest (Cordella \& Bonina, 2012). However, providing high quality services through improving professional and ethical values will reflect 
on the services provided to the citizens themselves. This view is supported when the deputy mayor for reginal service stated:

"If there are any service requests from citizens, we raise this issue on WhatsApp groups, and we consider all comments made by all members, and we then take a decision and send our response to the associated council's branches. If we do this through emails, it would have taken... [greater] time and effort.... We can take a picture of any memo to perform certain tasks and send it through to all associated departments to act upon immediately. Here is where the productivity and effectiveness are" (Code: P4-PSI-PV-P-GO-O61-I4).

Table 1 presents the outcome of each proposition evaluated in our model.

\begin{tabular}{llc}
\hline No & Proposition & Outcome \\
\hline P1 & $\begin{array}{l}\text { Social media capability is positively related to social media enabled public } \\
\text { engagement. }\end{array}$ & Supported \\
P2 & $\begin{array}{l}\text { Trust in social media applications is positively related to social media } \\
\text { enabled public engagement. }\end{array}$ & Supported \\
P3 & $\begin{array}{l}\text { Social media enabled public engagement is positively related to social media } \\
\text { enabled public service innovation. }\end{array}$ & Supported \\
P4 & $\begin{array}{l}\text { Social media enabled public service innovation is positively related to social } \\
\text { media enabled public value. }\end{array}$ & Supported \\
\hline
\end{tabular}

Table 1: Propositions analysis outcomes

\section{Limitations and Future Studies}

Our study suffers from two main limitations. First, this study is cross sectional in nature. A longitudinal study is needed in order to develop a richer understanding of social media public value creation phenomena. However, due to time constraints, such an approach was not adopted. Second, it is difficult to generalise our findings across all city councils located in Saudi Arabia. For future studies, the findings of this research would be a good empirical foundation for conducting quantitative studies to improve generalisability. Third, contextualisation is very important for IS theory development (Davison \& Martinsons, 2016). Any theory building models could profit when evaluated in a specific (cultural) context, however, our model has not directly investigated the cultural influences of the Saudi Arabian context and therefore further studies are needed to incorporate cultural influences.

Another round of empirical study involving multiple case study is currently in-progress. In that study, the viewpoint of multiple stakeholders including government officials and citizens representatives are considered.

\section{Conclusion and Contribution}

In this paper, we have reported an initial evaluation of a theory-driven model that links social media capability, trust in social media, public engagement, public service innovation and public value. Results from our pilot case study in a large municipality in Saudi Arabia provide support for the model. This initial validation of the model contributes to theory by enriching the IS and public administration literature and extending the applicability of theories applied in this study in a developing country. The model improved our understanding by creating a foundation for theory development in future social media research. The practical contribution of the evaluated model offers useful guidelines to those who are responsible for making decisions for formulating social media strategy officials at local government agencies. These guidelines identify those mechanisms and conditions that the officials should care about when social media is used in the councils. This in turn will facilitate obtaining the desired events from the use of social media within local government agencies. Our study also presents a methodological contribution to IS research; we have provided insights into the application of critical realism ontology and methodology for assessing public value creation through the use of social media applications.

\section{References}

Aladalah, M., Cheung, Y., \& Lee, V. C. (2016). Delivering public value: Synergistic integration via Gov 2.o. Paper presented at the System Sciences (HICSS), 2016 49th Hawaii International Conference on. 
Althaqafi, T., Rahim, M. M., \& Foster, S. (2018). Public value creation using social media applications for the local government context. Paper presented at the Twenty-Sixth European Conference on Information Systems (ECIS2018), UK.Portsmouth.

Andersen, L. B., Jørgensen, T. B., Kjeldsen, A. M., Pedersen, L. H., \& Vrangbæk, K. (2012). Public value dimensions: Developing and testing a multi-dimensional classification. International Journal of Public Administration, 35(11), 715-728.

Arnstein, S. R. (1969). A ladder of citizen participation. Journal of the American Institute of planners, 35(4), 216-224.

Bekmamedova, N., \& Shanks, G. (2014). Social media analytics and business value: a theoretical framework and case study. Paper presented at the 2014 47th Hawaii International Conference on System Sciences (HICSS).

Braojos-Gomez, J., Benitez-Amado, J., \& Llorens-Montes, F. J. (2015). How do small firms learn to develop a social media competence? International Journal of Information Management, 35(4), 443-458.

Brown, K., \& Osborne, S. P. (2012). Managing change and innovation in public service organizations: Routledge.

Carlsson, S. A. (2003). Advancing information systems evaluation (research): a critical realist approach. Electronic Journal of Information Systems Evaluation, 6(2), 11-20.

Cordella, A., \& Bonina, C. M. (2012). A public value perspective for ICT enabled public sector reforms: A theoretical reflection. Government Information Quarterly, 29(4), 512-520.

Criado, J. I., Sandoval-Almazan, R., \& Gil-Garcia, J. R. (2013). Government innovation through social media. In: Elsevier.

Davison, R. M., \& Martinsons, M. G. (2016). Context is king! Considering particularism in research design and reporting. Journal of Information Technology, 31(3), 241-249.

Dini, A. A., Wahid, F., \& Sæbo, Ø. (2016). Affordances and constraints of social media use in eParticipation: perspectives from Indonesian politicians.

Dobson, P., Myles, J., \& Jackson, P. (2007). Making the case for critical realism: Examining the implementation of automated performance management systems. Information Resources Management Journal, 20(2), 138.

Dwivedi, Y. K. (2009). Handbook of research on contemporary theoretical models in information systems: IGI Global.

Fletcher, A. J. (2017). Applying critical realism in qualitative research: methodology meets method. International Journal of Social Research Methodology, 20(2), 181-194.

Hong, H. (2013). Government websites and social media's influence on government-public relationships. Public Relations Review, 39(4), 346-356.

Hood, C. (1991). A public management for all seasons? Public administration, 69(1), 3-19.

Insight, G. M. (2018). Saudi Arabia Social Media Statistics 2018. Retrieved from https://www.globalmediainsight.com/blog/saudi-arabia-social-media-statistics/

Johannessen, M. R., Sæbø, Ø., \& Flak, L. S. (2016). Social media as public sphere: a stakeholder perspective. Transforming Government: People, Process and Policy, 1O(2), 212-238.

Jørgensen, T. B., \& Bozeman, B. (2007). Public values: An inventory. Administration \& Society, 39(3), 354-381.

Kane, G. C. (2015). Enterprise social media: Current capabilities and future possibilities. MIS Quarterly Executive, 14(1).

Kelly, G., Mulgan, G., \& Muers, S. (2002). Creating Public Value: An analytical framework for public service reform. London: Strategy Unit, Cabinet Office.

Kernaghan, K. (2003). Integrating values into public service: The values statement as centerpiece. Public Administration Review, 63(6), 711-719.

Lee-Kelley, L., \& Kolsaker, A. (2004). E-government: the" fit" between supply assumptions and usage drivers. Electronic Government, an International Journal, 1(2), 130-140.

Linders, D. (2012). From e-government to we-government: Defining a typology for citizen coproduction in the age of social media. Government Information Quarterly, 29(4), 446-454.

Malsbender, A., Hoffmann, S., \& Becker, J. (2014). Aligning capabilities and social media affordances for open innovation in governments. Australasian Journal of Information Systems, 18(3).

Mcknight, D. H., Carter, M., Thatcher, J. B., \& Clay, P. F. (2011). Trust in a specific technology: An investigation of its components and measures. ACM Transactions on Management Information Systems (TMIS), 2(2), 12.

Men, L. R., \& Tsai, W.-H. S. (2012). How companies cultivate relationships with publics on social network sites: Evidence from China and the United States. Public Relations Review, 38(5), 723730 . 
Mergel, I. (2013). A framework for interpreting social media interactions in the public sector. Government Information Quarterly, 30(4), 327-334.

Merickova, B. M., Svidronova, M. M., \& Nemec, J. (2016). Innovation in Public Service Delivery: Civic Participation in Slovakia. Africa's Public Service Delivery and Performance Review, 4(2).

Miles, M. B., \& Huberman, A. M. (1994). Qualitative data analysis: An expanded sourcebook: sage.

Moore, M. H. (1995). Creating public value: Strategic management in government: Harvard university press.

Moore, M. H. (2014). Public value accounting: Establishing the philosophical basis. Public Administration Review, 74(4), 465-477.

Mulgan, G., \& Albury, D. (2003). Innovation in the public sector. Strategy Unit, Cabinet Office, 1, 40.

Nabatchi, T., \& Amsler, L. B. (2014). Direct public engagement in local government. The American Review of Public Administration, 44(4_suppl), 63S-88S.

Newman, M., \& Robey, D. (1992). A social process model of user-analyst relationships. MIS quarterly, 249-266.

OECD. (2005). Guidelines for collecting and interpreting innovation data, Oslo Manual. In: Organisation for Economic Co-operation and Development Paris.

Omar, K., Scheepers, H., \& Stockdale, R. (2013). The use of social media in government 2.0 assessed through the public value lens. Paper presented at the 24th Australasian Conference on Information Systems (ACIS).

Oré, C., \& Sieber, S. (2011). Facebook and the World of Social Networks. IESE Business School Case Study.

Park, M. J., Choi, H., Kim, S. K., \& Rho, J. J. (2015). Trust in government's social media service and citizen's patronage behavior. Telematics and Informatics, 32(4), 629-641.

Rauniar, R., Rawski, G., Yang, J., \& Johnson, B. (2014). Technology acceptance model (TAM) and social media usage: an empirical study on Facebook. Journal of Enterprise Information Management, 27(1), 6-30.

Saldaña, J. a. (2016). The coding manual for qualitative researchers (3E [Third edition]. ed.): Los Angeles, Calif. London SAGE.

SaudiVision. (2017). Saudi Vision 2030. Retrieved from http://vision2030.gov.sa/en

Sayer, R. A. (2000). Realism and social science. London

Thousand Oaks, Calif.: London

Thousand Oaks, Calif. : Sage.

Srite, M. (1999). The influence of national culture on the acceptance and use of information technologies: An empirical study. AMCIS 1999 Proceedings, 355.

Tams, S., Thatcher, J. B., \& Craig, K. (2018). How and why trust matters in post-adoptive usage: The mediating roles of internal and external self-efficacy. The Journal of Strategic Information Systems, 27(2), 170-190.

Treem, J. W., \& Leonardi, P. M. (2013). Social media use in organizations: Exploring the affordances of visibility, editability, persistence, and association. Annals of the International Communication Association, 36(1), 143-189.

Tsang, E. W. (2014). Case studies and generalization in information systems research: A critical realist perspective. The Journal of Strategic Information Systems, 23(2), 174-186.

Volkoff, O., \& Strong, D. M. (2013). Critical Realism and Affordances: Theorizing IT-associated Organizational Change Processes. MIS quarterly, 37(3).

Warren, A. M., Sulaiman, A., \& Jaafar, N. I. (2014). Social media effects on fostering online civic engagement and building citizen trust and trust in institutions. Government Information Quarterly, 31(2), 291-301.

Webster, J., \& Watson, R. T. (2002). Analyzing the past to prepare for the future: Writing a literature review. MIS quarterly, xiii-xxiii.

Yin, R. K. (2017). Case study research and applications: Design and methods: Sage publications.

\section{Appendix 1}

Please Note: Please note:

$\mathrm{P}^{*}=$ Positive, $\mathrm{NU}^{*}=$ Neutrality, $\mathrm{N}^{*}=$ Negative, $\mathrm{GO}^{*}=$ Government official, $\mathrm{Cxx}=$ Comment number, Ixx $=$ Interviewee number, $\mathrm{P} 1=$ Proposition $1, \quad \mathrm{P} 2=$ Proposition 2, $\mathrm{P}_{3}=$ Proposition $3, \mathrm{P}_{4}=$ Proposition 4, $\mathrm{SMC}-\mathrm{PE}=$ Association between social media capability and public engagement, TISM-PE = Association between trust in social media and public engagement, PE-PSI= Association between public engagement and public service innovation., PSI-PV= Association between public service innovation and public value.

\begin{tabular}{|c|c|c|c|c|c|}
\hline Relationship & P* & $\mathrm{NU}^{*}$ & $\mathrm{~N}^{*}$ & GO* & Code Number \\
\hline \multirow{3}{*}{$P_{1}-S M C-P E$} & $\mathbf{P}$ & & & GO & $\left(P_{1}\right.$-SMC-PE-P-GO-Cxx-Ixx) \\
\hline & & NU & & Go & $\left(P_{1}-\mathrm{SMC}-\mathrm{PE}-\mathrm{NU}-\mathrm{GO}-\mathrm{Cxx}-\mathrm{Ixx}\right)$ \\
\hline & & & $\mathrm{N}$ & Go & $\left(P_{1}-\right.$ SMC-PE-N-GO-Cxx-Ixx) \\
\hline \multirow{3}{*}{ P2-TINSM-PE } & $\mathbf{P}$ & & & GO & (P2-TINSM-PE-P-GO-Cxx-Ixx) \\
\hline & & NU & & Go & $(\mathrm{P} 2-\mathrm{TINSM}-\mathrm{PE}-\mathrm{NU}-\mathrm{GO}-\mathrm{Cxx}-\mathrm{Ixx})$ \\
\hline & & & $\mathrm{N}$ & GO & (P2-TINSM-PE -N-GO-Cxx-Ixx) \\
\hline \multirow{3}{*}{ P3-PE-PSI } & $\mathbf{P}$ & & & GO & $\left(P_{3}-P E-P S I-P-G O-C x x-I x x\right)$ \\
\hline & & NU & & Go & (P3-PE-PSI- NU-GO-Cxx-Ixx) \\
\hline & & & $\mathrm{N}$ & GO & $\left(P_{3}\right.$-PE-PSI- N-GO-Cxx-Ixx) \\
\hline \multirow{3}{*}{ P4-PSI-PV } & $\mathbf{P}$ & & & Go & $\left(P_{5}-K S P-P V-P-C R-C x x-I x x\right)$ \\
\hline & & NU & & GO & (P5-KSP-PV-NU-CR-Cxx-Ixx) \\
\hline & & & $\mathrm{N}$ & GO & (P5-KSP-PV-N-GO-Cxx-Ixx) \\
\hline
\end{tabular}


Copyright: (C) 2018 authors. This is an open-access article distributed under the terms of the Creative Commons Attribution-NonCommercial 3.0 Australia License, which permits non-commercial use, distribution, and reproduction in any medium, provided the original author and ACIS are credited. 